\title{
Early and Midterm Results of Stent Endarterectomy for Left Anterior Descending Coronary Artery "Full Metal Jacket"
}

\author{
Rafik F. B. Soliman, MD, FRCS (Eng, CTH), ${ }^{1}$ Sunil Ohri, MB BS MD FRCS (Eng, Ed \& CTH) FESC, ${ }^{2}$ \\ Mohamed Hagag, MD, ${ }^{1}$ Fouad M Rasekh, MD \\ ${ }^{1}$ Cardiothoracic Surgery Department Faculty of Medicine, Menoufia University, Menoufia, Egypt; \\ ${ }^{2}$ Cardiac Surgery Department, Southampton University Hospital, Southampton, UK; \\ ${ }^{3}$ Cardiothoracic Surgery Department, Faculty of Medicine, Cairo University, Cairo, Egypt
}

\section{ABSTRACT}

Objective: Modern coronary interventional practice can result in coronary vessels that are totally stented. The term "full metal jacket" has been coined to refer to vessels that have an overlapping stent in series along the whole length of the vessel. This poses a serious challenge to surgical revascularization, particularly when a left internal thoracic artery (LITA) to the left anterior descending (LAD) needs to be undertaken. We evaluated the early and midterm results of on-pump coronary artery bypass grafting (CABG) following "stent endarterectomy" for the LAD with LITA to LAD grafting.

Methods: During October 2017 to September 2020, 21 patients presented with multi-vessel disease and a totally occluded LAD with a stent full metal jacket. No distal target for LITA grafting was available, despite a viable myocardial territory. The LAD was endarterectomised, removing the column of totally occluded stents with the medial wall of the vessel, leaving the proximal stent in place to avoid competitive flow. Long length anastomosis was then undertaken with the LITA graft. Postoperatively, patients were followed up clinically and by coronary computed tomography (CT) angiography at 6- and 18-month intervals. All patients were discharged on a combination of aspirin and warfarin for three months and then aspirin and clopidogrel for the rest of the first year and then aspirin alone for life.

Results: Patients had a mean age of $58.07 \pm 2.06$ yr. Sixteen $(76.2 \%)$ were males, $13(61.9 \%)$ patients were diabetics, $18(85.7 \%)$ were hypertensive, 15 (71.4\%) were dyslipidemic, six $(28.6 \%)$ were obese, $11(52.4 \%)$ were smokers, and five $(23.8 \%)$ had positive family history of ischemic heart disease (IHD). The number of grafts per patient ranged 3-5, with a mean cross-clamp time of $64.71 \pm 8.84 \mathrm{~min}$. There were no postoperative deaths nor MI clinically, by electrocardiogram (ECG) criteria nor by troponin or CK-MB. In-hospital complications included one $(4.8 \%)$ patient who

Received March 12, 2021;; accepted April 7, 2021.

Correspondence: Rafik F. B. Soliman, 25 Moby Al Din Abou Al Ezz Street, Dokki, Giza, Egypt, 12611, Telephone +201011102102; (e-mail: rafikfekry@ botmail.com. required re-exploration for bleeding, one (4.8\%) developed a superficial wound, and three (14.3\%) developed atrial fibrillation (AF), during their hospital stay. Mean hospital stay was $7.71 \pm 1.73$ days. All patients completed the 6-month follow up showing patent LITA to LAD with coronary CT angiography. One patient was lost to follow up after six months; five patients are awaiting their 18-month CT angiography, while $15(71.4 \%)$ patients have completed their 18 -month CT angiography, and all have a patent LITA to LAD.

Conclusions: Stent endarterectomy for a totally occluded LAD with a full metal jacket and viable myocardial territory is a safe procedure with good early and midterm results. This technique should be considered in these difficult cases presenting for revascularisation when no other option is available.

\section{INTRODUCTION}

Diffuse coronary artery disease constitutes a real challenge for revascularization either by percutaneous coronary intervention (PCI) or coronary artery bypass grafting (CABG). Both techniques often prove to be inadequate when dealing with severe diffuse coronary atherosclerosis. An option to achieve full revascularization is coronary endarterectomy, which was introduced in the 1950s with early discouraging results [Bailey 1957].

Recently, coronary endarterectomy is regaining its popularity as an adjunct to CABG in patients with severe diffuse coronary disease with excellent midterm and late survival rates and graft patency rates [Myers 2012].

The major benefit of left anterior descending endarterectomy is that the myocardium territory supplied by side branches (diagonals and septal perforators) of a diffusely diseased LAD will be relieved of ischemia. Patent LAD improve long-term survival and reduces morbidity and mortality [Kleisli 2005].

The introduction of drug-eluting stents to the clinical settings allowed treating diffuse coronary disease with multiple stents [Tsagalou 2005; Aoki 2005], which can result in coronary vessels that are totally stented. The term "full metal jacket" has been coined to refer to vessels that have stents in series along the whole length of the vessel. In-stent restenosis constitutes a major complication after PCI, even with the modern drug-eluting stent [Dangas 2010]. 
More patients with full metal jacket and subtotal or total occlusion are being referred for surgical revascularization. This pushes surgeons to intervene and save the myocardial territory at risk and remove the stents to achieve complete revascularisation specially when a LITA to the LAD needs to be undertaken. We evaluated the early and midterm results of on-pump CABG following "stent endarterectomy" for the LAD with LITA to LAD grafting.

\section{PATIENTS AND METHODS}

Patients: (IRB registration number 208/09 date 09/2017 cardiotech) Between October 2017 and September 2020, 328 patients underwent CABG by the same surgeon RS. Ninety-four patients had LAD coronary endarterectomy and 21 of them presented with multi-vessel disease and a totally occluded LAD with a stent full metal jacket. (Figure 1) No distal target for LITA grafting was available despite a viable myocardial territory. The LAD was endarterectomised, removing the column of overlapping stents with the atheromatous medial wall of the vessel. Long length anastomosis was then undertaken with the LITA graft.

Preoperative symptoms and risk factors all were recorded. Viability was confirmed by preserved LV thickness and absence of thinned out wall or dyskinesis in LAD territory. If there was any doubt, cardiac MRI was performed to confirm viability. Operative details and postoperative events, including all morbidities MI (clinically, by ECG criteria nor by troponin or CK-MB) and mortality were recorded. Institutional and individual patient consent was obtained. In addition, individual patient consent was obtained for computed tomography (CT) angiography examination of stent endarterectomy patients.

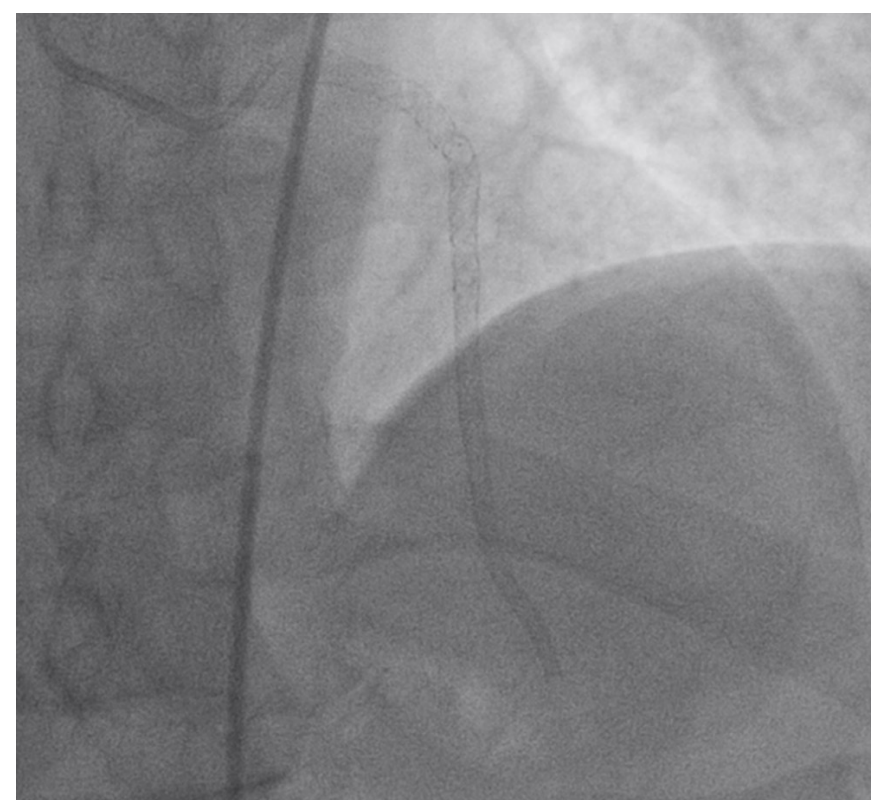

Figure 1. Coronary angiogram showing the LAD full metal jacket.
Cardiopulmonary bypass (CPB) and surgical technique: Median sternotomy with $\mathrm{CPB}$ was the standard approach. $\mathrm{CPB}$ was established, using standard ascending aortic and right atrial cannulations with systemic cooling to $32 \mathrm{C}$. Antegrade cold blood cardioplegia was used for myocardial protection through the aortic root and, in some cases, supplemented with retrograde cardioplegia through the coronary sinus. Topical myocardial cooling was used in all cases. LAD stent endarterectomy was performed by opening the disease left anterior descending artery directly over the stent and then carefully dissecting the plane in the arterial wall to remove the intima, neointima, stent and old plaque all together as one block. A gentle traction on the plaque and stent all together was performed to deliver out the stent from the distal and then proximal LAD. (Figure 2) (Figure 3) The most proximal totally occluded stent was left in place to avoid competitive flow. Extended arteriotomy was performed for completion of the stent endarterectomy. LIMA was anastomosed to the endarterectomized LAD artery directly as extended end-to-side anastomosis onto the LAD using 7/0 prolene on $9 \mathrm{~mm}$ needle. (Figure 4) Other targets were revascularized as usual either with radial artery and/or great
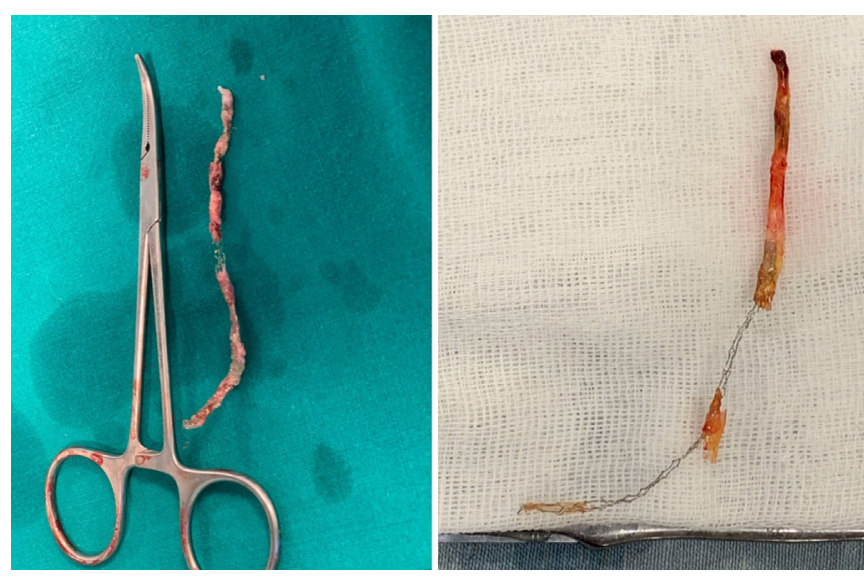

Figure 2. Multiple overlapping stents (full metal jacket) removed together with the atheromatous plaque and neointima in 2 different cases.

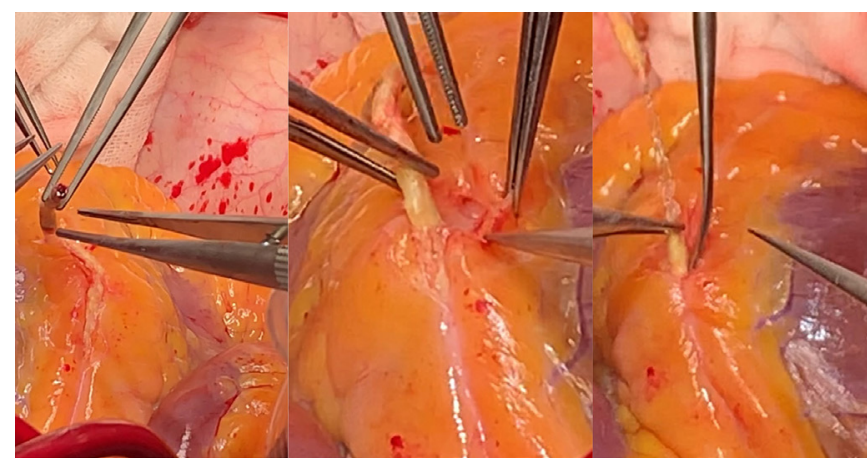

Figure 3. Stent endarterectomy of the distal and proximal LAD removing totally occluded LAD full metal jacket. 
saphenous vein conduits. After cardiopulmonary bypass the heparin was reversed.

Postoperative and follow up: All postoperative data including inotropes requirement, arrythmias, re-exploration, perioperative MI, length of ICU and hospital stay, and postoperative wound infection.

The anticoagulation was as follows:

1. After operation therapeutic heparin to keep APPTT 1.5 2 until we reach the target INR.

2. Single antiplatelet, usually aspirin $100 \mathrm{mg}$ and warfarin to keep INR around 2 for the first 3 months.

3. After 3 months dual antiplatelet therapy aspirin and clopidogrel for the rest of the first year.

4. After one-year, single antiplatelet therapy.

Postoperatively, patients were followed up clinically and by using coronary CT angiography at 6 - and 18 -month intervals. (Figure 5)

Statistical analysis: Collected data was expressed as mean and standard deviation $\left(M_{ \pm} \mathrm{SD}\right)$ for quantitative variables or number and percent (n, \%) for qualitative ones. Statistical analysis was performed using IBM Statistical Package for Social Science (SPSS) version 20 (IBM corporation, Chicago, IL, USA).

\section{RESULTS}

Between October 2017 and September 2020, 21 patients presented with multi-vessel disease and a totally occluded LAD after stenting with a full metal jacket. No distal target for LITA grafting was available, despite a viable myocardial territory. The LAD of those patients was endarterectomised. They were $58.07 \pm 2.06$ years old and $76.2 \%$ of them were males. Patient characteristics are listed in Table 1. (Table 1)

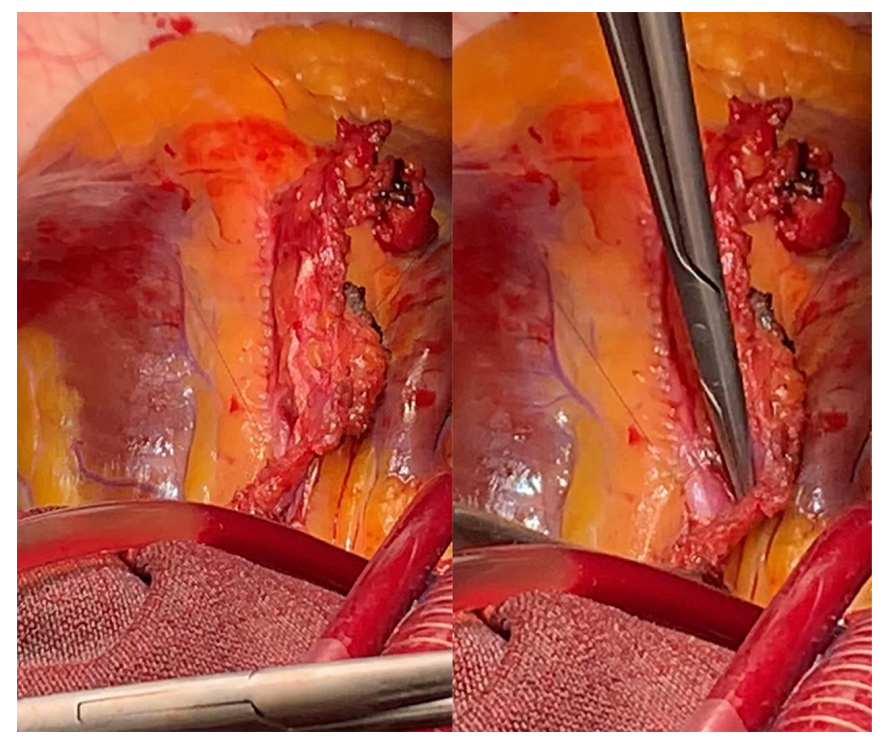

Figure 4. Extended onlay LIMA patch anastomosis to endarterectomized LAD.
Risk factors screening revealed that the most common risk factor was hypertension in $85.7 \%, 61.9 \%$ of patients were diabetic, $71.4 \%$ dyslipidemic and $52.4 \%$ smokers, while the least encountered risk factors were obesity $(28.6 \%)$ and positive family history (23.8\%).

Mean cross-clamp time was $64.71 \pm 8.84$ with $52.4 \%$ of the patients received three grafts. Intraoperatively, seven (33.3\%) patients required inotropic support after bypass and only three $(14.3 \%)$ patients needed cardioversion to restore sinus rhythm. (Table 2)

Average overall hospital stay was $7.71 \pm 1.73$ days, entailing the whole patient's stay within hospital from admission until discharge. Unfortunately, some patients suffered few complications. (Table 3) These include atrial fibrillation in three $(14.3 \%)$ patients, and one patient underwent exploration for high drainage revealing consumptive coagulopathy without surgical bleeding. Later, this patient developed a superficial wound infection that healed with medical treatment. No patient suffered myocardial infarction since surgery until the last point of follow up; no admission with cardiac events nor need for revascularization were noted in any patient.

All patients attended the 6-month follow-up visit with patent all conduit on CT coronary angiography; 15 (71.4\%) had their 18-month follow-up visit and had patent all conduits. We lost follow up of one patient and still are waiting for the 18-month follow up of the remaining five (23.8) patients. (Table 4)
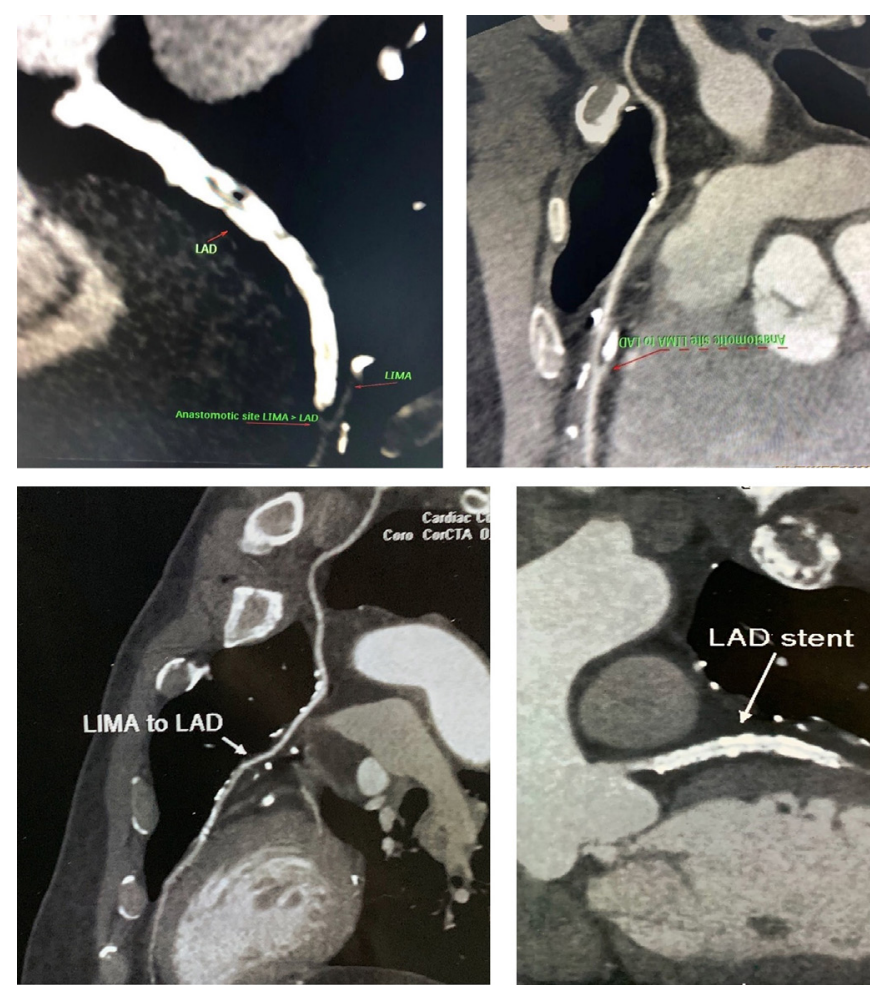

Figure 5. CT coronary angiogram confirming 2 different cases with patent LITA to LAD with good distal run off at 18-month follow up post-surgery and showing proximal stent left in place to avoid competitive flow. 


\section{DISCUSSION}

The incidence of coronary in-stent restenosis ranges from $14 \%$ to $60 \%$ [Kappetein 2013; Fukui 2005]. Few studies reported on the efficacy and safety of endarterectomy with concomitant $\mathrm{CABG}$, suggesting that it is the best procedure in such patients, particularly in cases of "full metal jacket" or in diffusely diseased vessels [Fukui 2005; Demirsoy 2006; Filippone 2018; Zattera 2010].

Twenty-one patients were included in the present study, thereby the present study presents one of the largest series of patients with totally occluded LAD stent full metal jacket undergoing this procedure, as most previous studies consisted of either a case report of a single patient or a series of three to 12 patients [Fukui 2005; Demirsoy 2006; Filippone 2018; Zattera 2010; Shapira 1999; Srimurugan 2018].

Coronary endarterectomy can be performed with either on-pump or off-pump technique. We used the on-pump technique on all patients. Previous studies reported the safety of off-pump coronary endarterectomy [Eryilmaz 2003; Nishigawa 2015]. Nevertheless, off-pump technique may be challenging in a dilated or poorly functioning heart. As LAD endarterectomy and on-lay anastomosis are known to require longer time than usual grafting, an increased risk of ischemia to the myocardium is expected.

There are two main surgical approaches for coronary endarterectomy: the closed (traction) and open (direct vision) approaches. Each approach possesses its own advantages and

Table 1. Demographics

\begin{tabular}{lc}
\hline Variable & $N=21$ \\
\hline Age (years) & \\
Mean \pm SD & $58.07 \pm 2.06$ \\
Range & $54-61$ \\
Sex & \\
Male & $16(76.2 \%)$ \\
Female & $5(23.8 \%)$ \\
Risk factors & \\
Diabetes mellitus & $13(61.9 \%)$ \\
Hypertension & $18(85.7 \%)$ \\
Dyslipidemia & $15(71.4 \%)$ \\
Obesity & $6(28.6 \%)$ \\
Smoking & $11(52.4 \%)$ \\
Family history & $5(23.8 \%)$ \\
EF & \\
Mean \pm SD & $49.29 \pm 3.5$ \\
Range & $44-57$ \\
EuroScore II & \\
Mean \pm SD & $1.02 \pm 0.37$ \\
Range & $0.5-1.91$ \\
&
\end{tabular}

disadvantages. Despite the relative simplicity and easiness of reconstruction in the closed (traction) approach [Bailey 1957; Effler 1964], it sometimes is impossible to remove completely the atheromatous plaques as the LAD has diagonal branches in two different planes. It also is difficult to prevent intimal flaps [Keogh 1991]. Regarding the open approach, the atheromatous plaques can be completely removed under direct vision [Sommerhaug 1990; Beretta 1992]. However, the open approach necessitates patch closure of the LAD and bypass grafting [Tiruvoipati 2005]. Open coronary endarterectomy was associated with better midterm patency on angiographic follow up compared with traction coronary endarterectomy [Nishi 2005]. All patients in the present study underwent open stent endarterectomy.

Reconstruction of coronary artery after endarterectomy can be performed by numerous methods. The most commonly used reconstruction strategies, following endarterectomy of the LAD, utilize either a combination of saphenous vein patch with LITA grafting [Fundarò 1987] or LITA onlay-patch grafting [Shapira 1988]. There is debate concerning whether one strategy is superior to the other. Myers et al. [Myers 2012] reported the lack of significant difference of these two reconstruction strategies on long-term survival. However, Beretta et al. [Beretta 1992] reported lower mortality rate and improved long-term survival in patients with the LITA onlay-patch grafting compared with those who underwent saphenous vein grafting. In the present study, we used LITA onlay-patch in all cases.

Regarding postoperative course of the patients, no major complications were encountered. Inotropic support after CABG was required in $33.3 \%$ patients. Cardioversion was performed in $14.3 \%$ of patients to restore sinus rhythm. Atrial fibrillation was detected in three patients (14.3\%). One

Table 2. Operative data

\begin{tabular}{|c|c|}
\hline Variable & $N=21$ \\
\hline \multicolumn{2}{|l|}{ Operative time (minutes) } \\
\hline Mean \pm SD & $245.50 \pm 30.01$ \\
\hline Range & $196-294$ \\
\hline \multicolumn{2}{|l|}{ Cross-clamp time (minutes) } \\
\hline Mean \pm SD & $64.71 \pm 8.84$ \\
\hline Range & $52-84$ \\
\hline \multicolumn{2}{|l|}{ Total bypass time (minutes) } \\
\hline Mean \pm SD & $102.07 \pm 12.52$ \\
\hline Range & $84-127$ \\
\hline \multicolumn{2}{|l|}{ Number of grafts } \\
\hline 3 & $8(38.1 \%)$ \\
\hline 4 & $11(52.4 \%)$ \\
\hline 5 & $2(9.5 \%)$ \\
\hline Need for inotropic support & $7(33.3 \%)$ \\
\hline Need for cardioversion & $3(14.3 \%)$ \\
\hline
\end{tabular}


patient was diagnosed to have consumptive coagulopathy without surgical bleeding, and this patient developed superficial wound infection that healed with medical treatment. No patient suffered myocardial infarction since surgery until the last point of follow up; no admission with cardiac events nor need for revascularization were noted in any patient. These findings suggest the reasonable efficacy and safety of stent endarterectomy combined with CABG in patients with full metal jacket in-stent restenosis.

Previous studies reported comparable outcomes. Fukui et al. [Fukui 2005] described a series of 11 patients. They reported patency of all LIMA patches and LAD arteries as well as the absence of in-hospital complications in all patients, except for one patient with low output syndrome. Zattera et al. [Zattera 2010] reported a case of a man who remained asymptomatic for two years post-coronary stent endarterectomy and CABG.

Demir et al. [Demir 2015] described six patients with LAD stent endarterectomy and CABG. Their patients underwent an uneventful postoperative period and were asymptomatic during the follow-up period, which ranged from three to 104 months. None of the patients suffered from myocardial infarction, required reintervention, or died during the follow up. Examination with coronary angiography confirmed patency of all grafts.

Nishigawa et al. [Nishigawa 2015] described a series of 12 patients who underwent coronary stent endarterectomy with concomitant CABG. None of their patients suffered

Table 3. Postoperative data

\begin{tabular}{|c|c|}
\hline Variable & $N=21$ \\
\hline \multicolumn{2}{|c|}{ Duration of mechanical ventilation (hours) } \\
\hline Mean \pm SD & $5.29 \pm 1.59$ \\
\hline Range & $3-8$ \\
\hline \multicolumn{2}{|c|}{ Duration of inotropic support (hours) } \\
\hline Mean \pm SD & $3.43 \pm 5.17$ \\
\hline Range & $0-15$ \\
\hline IABP & 0 \\
\hline Myocardial infarction & 0 \\
\hline Exploration & $1(4.8 \%)$ \\
\hline Atrial fibrillation & $3(14.3 \%)$ \\
\hline Renal dysfunction & 0 \\
\hline Chest infection & 0 \\
\hline Wound infection & $1(4.8 \%)$ \\
\hline \multicolumn{2}{|l|}{ ICU stay (hours) } \\
\hline Mean \pm SD & $44.00 \pm 6.25$ \\
\hline Range & $30-54$ \\
\hline \multicolumn{2}{|l|}{ Hospital stay (days) } \\
\hline Mean \pm SD & $7.71 \pm 1.73$ \\
\hline Range & $5-10$ \\
\hline
\end{tabular}

from in-hospital deaths, strokes, or myocardial infarctions. No deaths were recorded in their series after a median follow-up period of 24 months. Filippone et al. [Filippone 2018] reported on two men who underwent stent endarterectomy on LAD and CABG. They stated that the postoperative period was uneventful, and patency of the LAD bypass graft was shown on coronary computed tomography angiography 6 months postoperative. Srimurugan et al. [Srimurugan 2018] reported on three men with in-stent restenosis who underwent coronary endarterectomy with stent removal and CABG. Two of them were asymptomatic during a 3-year follow up after surgery, while follow-up data for the third patient was not reported.

Shapira et al. [Shapira 1999] stated the lack of significant differences in rates of death and morbidity between combined coronary endarterectomy with $\mathrm{CABG}$ and $\mathrm{CABG}$ alone. Tiruvoipati et al. [Tiruvoipati 2005] reported that comorbidities, rather than the procedure of coronary endarterectomy, were potentially contributing to the higher mortality rate observed after endarterectomy.

The difficulty of removal of stent with atheromatous core was reported by Nishigawa et al. [Nishigawa 2015] to be higher in re-stenosed drug-eluting stents than with restenosed bare-metal stents. This most probably is due to the severe stent-induced inflammatory change in the LAD by the former type of stents.

The most feared major complication following coronary stent endarterectomy in cases of in-stent restenosis is the occurrence of acute thrombosis in the stent endarterectomized artery [Uchimuro 2009]. Thrombosis occurs in these cases because of the loss of endothelium, exposing the subendothelial tissue to the blood stream, and consequently the coagulation cascade is triggered. To prevent such disastrous complication in the reconstructed coronary artery, it is customary to prescribe antiplatelet therapy. We prescribed aspirin and along with intravenous infusion of low-molecular weight heparin followed by oral administration of warfarin for the first three months, followed by both aspirin and clopidogrel for the rest of the first year, then aspirin for life. This practice was reported by several earlier studies [Fukui 2005; Srimurugan 2018; Nishigawa 2015] and seems to be effective in preventing this complication.

Another point to be considered carefully during stent endarterectomy is avoiding removal of the most proximal

Table 4. Follow up

\begin{tabular}{lc}
\hline Variable & $N=21$ \\
\hline 6 months follow up & \\
Patient & $21(100 \%)$ \\
18 months follow up & \\
Patent & $15(71.4 \%)$ \\
Pending result & $5(23.8 \%)$ \\
Lost follow up & $1(4.8 \%)$
\end{tabular}


stenotic lesion. The reason is to avoid the occurrence of flow competition. Yilmazkaya et al. [Yilmazkaya 2008] observed a string sign of the LITA during angiography in two out of four patients after coronary stent endarterectomy with in-stent restenosis of LAD, and they attributed this sign to graft competition. We did not observe such a sign in our series of patients as we always leave the most proximal stent in place.

Study limitations: Our study is an observational singlesurgeon evaluation of a small group of patients undergoing CABG with stent CEA; however, it presents our primary results addressing such a group of patients. Patients refusing follow-up imaging were not included in the study. The lack of a control group treated with revascularization (CABG or $\mathrm{PCI}$ ) to other targets and leaving the totally occluded LAD metal jacket in situ, as well as the absence of a medical treatment arm precludes the superiority of the demonstrated surgical concept.

\section{CONCLUSION}

Patients with totally occluded full LAD metal jacket despite viable $\mathrm{LAD}$ myocardial territory are often judged not to be candidates for PCI or surgical revascularization. We believe that following our elaborated algorithm, stent endarterectomy for a totally occluded LAD with a full metal jacket and viable myocardial territory is a safe procedure that allows complete revascularization with good early and midterm results. This technique should be considered in these difficult cases presenting for revascularisation when no other option is available.

\section{REFERENCES}

Aoki J, Ong AT, Rodriguez Granillo GA, McFadden EP, van Mieghem CA, Valgimigli M, et al. 2005. "Full metal jacket" (stented length $>$ or $=64$ $\mathrm{mm})$ using drug-eluting stents for de novo coronary artery lesions. Am Heart J. 150(5):994-9.

Bailey CP, May A, Lemmon WM. 1957. Survival after coronary endarterectomy in man. J Am Med Assoc. 164(6):641-6.

Beretta L, Lemma M, Vanelli P, DiMattia D, Bozzi G, Broso P, et al. 1992. Coronary "open" endarterectomy and reconstruction: short- and long-term results of the revascularization with saphenous vein versus IMA-graft. Eur J Cardiothorac Surg. 6(7):382-6; discussion 7.

Dangas GD, Claessen BE, Caixeta A, Sanidas EA, Mintz GS, Mehran R. 2010. In-stent restenosis in the drug-eluting stent era. J Am Coll Cardiol. 56(23):1897-907.

Demir T, Egrenoglu MU, Tanrikulu N, Cizgici AY, Yildirim KI, Dindar I, et al. 2015. Surgical Revascularization of the Left Anterior Descending Artery with Multiple Failed Overlapping Stents. J Card Surg. 30(12):877-80.

Demirsoy E, Tandogan A, Yilmaz O, Tukenmez F, Tufekcioglu S, Sonmez B. 2006. Grafting the restenosed coronary artery after removal of multiple failed stents by endarterectomy. Tex Heart Inst J. 33(2):262-3.

Effler DB, Groves LK, Sones FM, Jr., Shirey EK. 1964. Endarterectomy in the Treatment of Coronary Artery Disease. J Thorac Cardiovasc Surg. 47:98-108.

Eryilmaz S, Inan MB, Eren NT, Yazicioglu L, Corapcio lu T, Akalin H. 2003. Coronary endarterectomy with off-pump coronary artery bypass surgery. The Annals of Thoracic Surgery. 75(3):865-9.

Filippone G, Calia C, Vacirca SR, Caruana G, Re MR, Giardina C, et al. 2018. Coronary endarterectomy to facilitate bypass surgery for patients with extensive stenting of the left anterior descending artery. Coron Artery Dis. 29(4):359-60.

Fukui T, Takanashi S, Hosoda Y. 2005. Coronary endarterectomy and stent removal in patients with in-stent restenosis. Ann Thorac Surg. 79(2):558-63; discussion 63.

Fundarò P, Di Biasi P, Santoli C. 1987. Coronary endarterectomy combined with vein patch reconstruction and internal mammary artery grafting: experience with 18 patients. Tex Heart Inst J. 14(4):389-94.

Hoffmann R, Mintz GS. 2000. Coronary in-stent restenosis - predictors, treatment and prevention. Eur Heart J. 21(21):1739-49.

Kappetein AP, Head SJ, Morice MC, Banning AP, Serruys PW, Mohr FW, et al. 2013. Treatment of complex coronary artery disease in patients with diabetes: 5 -year results comparing outcomes of bypass surgery and percutaneous coronary intervention in the SYNTAX trial. Eur J Cardiothorac Surg. 43(5):1006-13.

Keogh BE, Bidstrup BP, Taylor KM, Sapsford RN. 1991. Angioscopic evaluation of intravascular morphology after coronary endarterectomy. Ann Thorac Surg. 52(4):766-71; discussion 71-2.

Kleisli T, Cheng W, Jacobs MJ, Mirocha J, Derobertis MA, Kass RM, et al. 2005. In the current era, complete revascularization improves survival after coronary artery bypass surgery. J Thorac Cardiovasc Surg. 129(6):1283-91

Kobayashi Y, De Gregorio J, Kobayashi N, Akiyama T, Reimers B, Finci L, et al. 1999. Stented segment length as an independent predictor of restenosis. J Am Coll Cardiol. 34(3):651-9.

Myers PO, Tabata M, Shekar PS, Couper GS, Khalpey ZI, Aranki SF. 2012. Extensive endarterectomy and reconstruction of the left anterior descending artery: early and late outcomes. J Thorac Cardiovasc Surg. 143(6):1336-40.

Nishi H, Miyamoto S, Takanashi S, Minamimura H, Ishikawa T, Kato Y, et al. 2005. Optimal method of coronary endarterectomy for diffusely diseased coronary arteries. Ann Thorac Surg. 79(3):846-52; discussion 52-3.

Nishigawa K, Fukui T, Takanashi S. 2015. Off-pump coronary endarterectomy with stent removal for in-stent restenosis in the left anterior descending artery. Interact Cardiovasc Thorac Surg. 21(5):594-7.

Shapira N, Lumia FJ, Gottdiener JS, Germon P, Lemole GM. 1988. Adjunct endarterectomy of the left anterior descending coronary artery. Ann Thorac Surg. 46(3):289-96.

Shapira OM, Akopian G, Hussain A, Adelstein M, Lazar HL, Aldea GS, et al. 1999. Improved clinical outcomes in patients undergoing coronary artery bypass grafting with coronary endarterectomy. Ann Thorac Surg. 68(6):2273-8.

Sommerhaug RG, Wolfe SF, Reid DA, Lindsey DE. 1990. Early clinical results of long coronary arteriotomy, endarterectomy and reconstruction combined with multiple bypass grafting for severe coronary artery disease. Am J Cardiol. 66(7):651-9.

Srimurugan B, Sigler M, Sankar NM, Cherian KM. 2018. In-stent restenosis: surgical and histopathological perspective. 26(2):114-9. 
Tiruvoipati R, Loubani M, Lencioni M, Ghosh S, Jones PW, Patel RL. 2005. Coronary endarterectomy: impact on morbidity and mortality when combined with coronary artery bypass surgery. Ann Thorac Surg. 79(6):1999-2003.

Tiruvoipati R, Loubani M, Peek G. 2005. Coronary endarterectomy in the current era. Curr Opin Cardiol. 20(6):517-20.

Tsagalou E, Chieffo A, Iakovou I, Ge L, Sangiorgi GM, Corvaja N, et al. 2005. Multiple overlapping drug-eluting stents to treat diffuse disease of the left anterior descending coronary artery. J Am Coll Cardiol. 45(10):1570-3.
Uchimuro T, Fukui T, Mihara W, Takanashi S. 2009. Acute thrombosis after endarterectomy of stented left anterior descending artery. Interact Cardiovasc Thorac Surg. 8(6):663-5.

Yilmazkaya B, Circi R, Circi UP, Gurkahraman S, Yukselen MA, Yondem OZ, et al. 2008. Surgical approaches in left anterior descending artery in-stent stenosis. Ann Thorac Surg. 85(5):1586-90.

Zattera GF, Grande AM, Gaeta R, Savasta M, Lentini S, Viganò M. 2010. Reconstruction of anterior descending artery after removal of stents. Asian Cardiovasc Thorac Ann. 18(3):291-3. 